\title{
UNA «VIRGEN REZANDO» INÉDITA DE ZURBARÁN
}

El cuadro con la Virgen rezando que presentamos (Fig. 1) se encuadra perfectamente en el estilo y temática del artista extremeño. Pintado sobre lienzo, desafortunadamente, reentelado, lo que nos impide un análisis más riguroso de la tela, las dimensiones de la obra son $67 \times 48$ centímetros. Este tamaño nos hace pensar en un encargo de devoción privada. Desconocemos si ha sido objeto de recortes aunque sí se aprecia algún repinte en el fondo oscuro. De ser así podría haber formado parte de una composición con el Niño Jesús y, tal vez, con más figuras pudiéndose tratar de una adoración de los pastores o tema similar.

Por lo que se refiere a la temática, el pintor extremeño nos tiene muy acostumbrados a la representación de Crucificados de gran intensidad emocional, de santos aislados, entre los que destaca San Francisco de Asís, además de las santas en las que pone el acento, más que en la expresión arrobada del rostro, en la belleza y calidad de los atuendos. En cuanto a la imagen de María, Zurbarán repitió en numerosas ocasiones el tema de la Inmaculada Concepción; dada su formación sevillana, sus imágenes parten de los prototipos de Pacheco y, por ello, nos encontramos con una imagen infantil, con las manos juntas casi siempre, un manto azul sobre la túnica rosa o blanca y un conjunto de querubines a sus pies. También la representó en varias ocasiones como niña, ya en éxtasis (Metropolitan Museum, Nueva York), ya en oración (Granada, Instituto Gómez-Moreno y Ermitage de Leningrado), ya dormida (Catedral de San Salvador, Jerez de la Frontera). El cuadro que estudiamos en estas páginas presenta una iconografía poco frecuente puesto que no se conocían, hasta ahora, imágenes de la Virgen María orando y más adulta de lo que suele aparecer en las obras en las que Zurbarán la pinta sola. Sin embargo, podríamos buscar parecidos de la modelo con otras representaciones de María en otros cuadros del maestro, en concreto nos referimos a los que pintara para el altar mayor de la Cartuja de la Defensión en Jerez de la Frontera.

Este fabuloso conjunto, uno de los más bellos del Siglo de Oro español, fue desmembrado en el siglo xIx habiendo sido objeto de muy importantes estudios ${ }^{1}$. Los cuadros del mismo que aquí nos interesan se encuentran hoy en el Museo de Escultura y de Pintura de Grenoble (Francia), se trata de «La Anunciación» $(2,67 \times 1,85 \mathrm{~m}$.), «La Adoración de los Pastores» $(2,67 \times$ 1,85 m.) (Fig. 2), y «La Adoración de los Reyes Magos» (2,64 × 1,76 m.). En todos ellos aparece una virgen que presenta unos rasgos fisonómicos muy parecidos a la modelo de nuestro cuadro. A simple vista, la imagen que nos ocupa parece tener una nariz algo más alargada y, tal vez, algo más de edad pero siempre dentro de un parecido grande. Estas diferencias han de deberse a las sombras que inciden sobre la cabeza y que, en ocasiones, modifican los contornos, aún tratándose de los mismos rasgos. También puede entrar en juego la intención del pintor de dulcificar o embellecer un rostro. Si nos detenemos con más calma, la similitud es mayor con la cara que aparece en «La adoración de los pastores», lo que tal vez sea debido a la postura similar de ambas. Las dos miran hacia abajo aunque una vuelta hacia la derecha y otra hacia la izquierda y siendo, el juego de luces y sombras, más acentuado en la de Jerez. Esta postura es la que nos lleva a pensar en la ausencia de un Niño Jesús debajo de las manos de María en el cuadro que estudiamos. No obstante, en ambos rostros encontramos una frente

\footnotetext{
1 Ver Catálogo de la Exposición «Zurbarán», Museo del Prado, 3 de mayo/30 de julio de 1988, pp. 253 y ss. Entre los estudios, ver: Pemán, C.: «La reconstrucción del retablo de la Cartuja de Jerez de la Frontera», Archivo Español de Arte, 1950, XXIII, pp. 203-227; Pemán: «Zurbarán y otros estudios sobre pintura del XVII español», Madrid, 1989. Otros estudios: Liedtke, W.: «Zurbaran's Jerez Altarpiece Reconstructed», Apollo, march, 1988, pp. 153-162. Odile Delenda publicó sus opiniones en el Catálogo de la Exposición de Zurbarán celebrado en el Museo del Prado, citado supra y «Sur la terre comme au ciel», Zurbarán. Le retable de Jerez de la Frontera», Belguique, 1999; por último, Navarrete Prieto, B.: «Aportaciones a los Zurbaranes de la Cartuja de Jerez», Separata del libro «Zurbarán: Estudio y Conservación de los Monjes de la Cartuja de Jerez», Madrid, 1998. de Algueró M. y otros. Para el estudio de estos cuadros ver también Caturla, Ma Luisa: «Francisco de Zurbarán», traducción, adaptación y estudio crítico por Odile Delenda, París, 1994, p. 150 y ss.
}

$A E A$, LXXVI, 2003, 302, pp. 187 a 205 

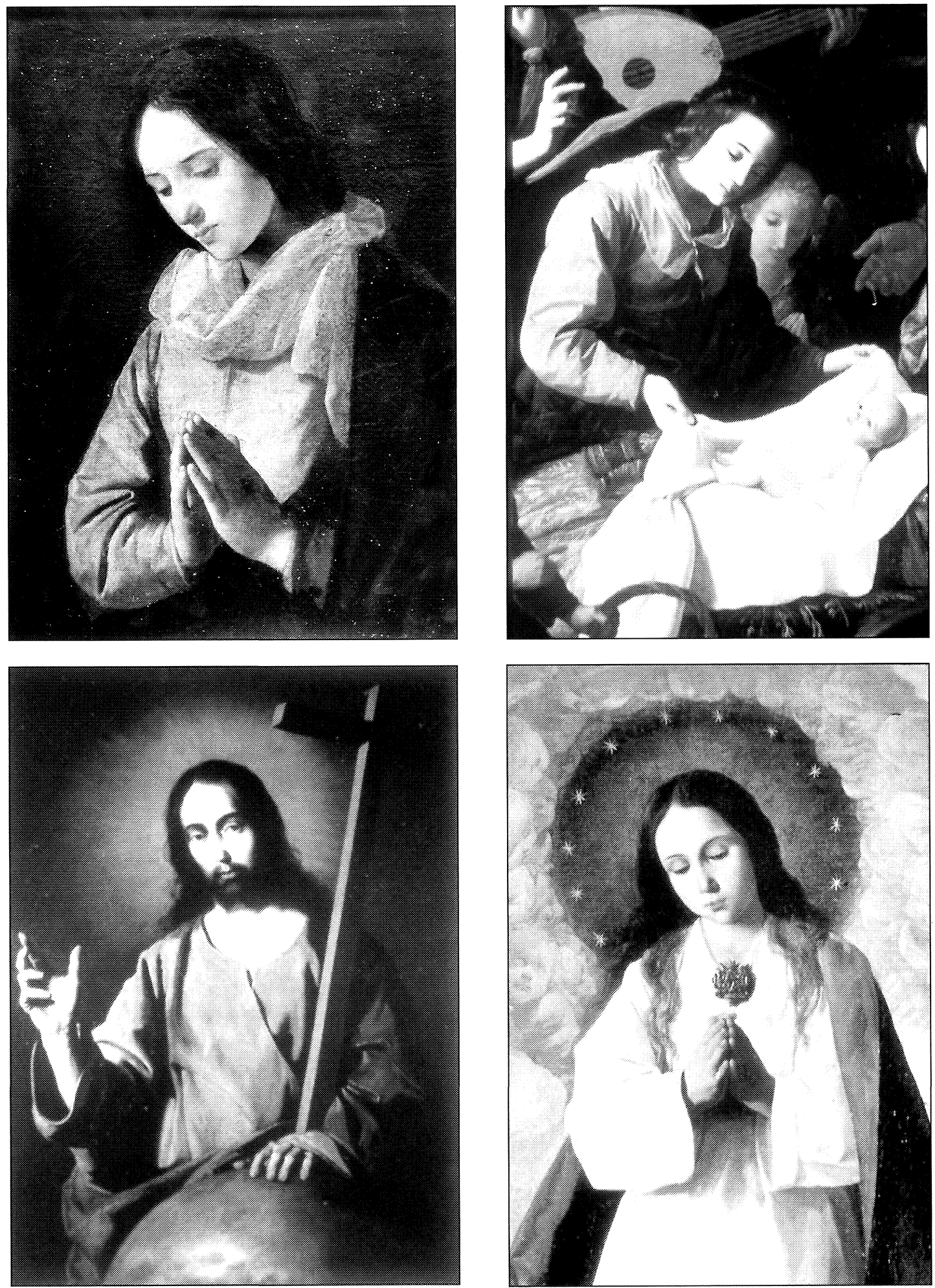

Fig. 1. Francisco de Zurbarán: La Virgen María rezando. Madrid. Colección privada.

Fig. 2. Francisco de Zurbarán: La Adoracion de los Pastores, detalle. Grenoble, Musée de Peinture et de Sculpture.

Fig. 3. Francisco de Zurbarán: El Salvador bendiciendo. Madrid, Museo del Prado.

Fig. 4. Francisco de Zurbarán: Inmaculada Concepción, detalle. Sigüenza, Museo Diocesano.

AEA, LXXVI, 2003, 302, pp. 187 a 205 
ancha y muy despejada, con unas cejas largas y arqueadas y unos labios carnosos así como la nariz que mencionábamos antes y una barbilla puntiaguda.

Tampoco se puede descartar el parecido físico con otras figuras de la Virgen María pintadas por el mismo artista o, incluso, con santas salidas de mano del pintor extremeño y que va más allá del mero aire similar que ofrecen todos los cuadros pintados por una misma mano, en este caso la de Zurbarán. Es muy posible que nos encontremos ante una adolescente que utilizó para unos cuadros determinados y que le sirvió en más de una ocasión. Por ello nos hemos permitido pensar en alguien próximo al artista y del cual se hubiera valido para su obra. Buscando entre los familiares más próximos, el 13 de julio de 1623 se celebra en Llerena el bautizo de Isabel Paula, tercer vástago, tras María y Juan, del matrimonio formado por Francisco de Zurbarán y su primera esposa María Páez ${ }^{2}$. Según los documentos conservados hasta el momento, esta niña permaneció con su padre tras el fallecimiento de su madre, del de la segunda esposa de éste, Beatriz de Morales, que lo hizo en 1639, y después del matrimonio de sus dos hermanos, declarándose «doncella» en $1640^{3}$. No tiene nada de extraño que nuestro artista la utilizara como modelo. A todo esto hay que unir que, en 1638, fecha alrededor de la cual nos movemos, tenía quince años. Esta edad, que viene a coincidir con la que podría tener la Virgen en los cuadros de la Defensión, siendo algo mayor en la obra que estamos estudiando, además de la semejanza física con otros cuadros que también mencionamos, nos permite aventurar esta hipótesis ${ }^{4}$.

Otro elemento que acentúa la semejanza entre esta imagen de la Virgen y los cuadros de la Cartuja de Jerez que nos están sirviendo de referencia, son las vestiduras. El paño que rodea el cuello de María es de un tejido blanco, similar al que tiene en «La Adoración de los pastores», y mucho menos transparente que el velo que cubre su cabeza en los otros dos lienzos. Se podría aducir una diferencia en tratamiento, sin embargo aquí nos encontramos con una necesidad de limpieza de nuestra obra en la que los barnices, oscurecidos, prestan un tinte dorado al cuadro, que no aparece en los de la Cartuja. La posición del pañuelo es algo distinta también pero la sensación de volumen, la textura así como lo quebrado de los pliegues, es algo propio del maestro extremeño tan famoso por los hábitos blancos que pintara en sus cuadros de monjes.

Por lo que respecta al vestido, éste se compone de túnica y manto. La primera es idéntica a la de la Virgen en los cuadros de la Cartuja, el color es rojo aunque algo más dorado por efecto de la oxidación de los barnices que ya mencionábamos más arriba. Este mismo color está presente en multitud de obras de Zurbarán, baste recordar parte de las Inmaculadas (Museo del Prado, Museo de Arte de Cataluña, Museo Cerralbo, Ayuntamiento de Sevilla ...) o la imagen de «El Salvador bendiciendo»que se encuentra en el Museo del Prado de Madrid (Fig. 3). Son éstos los rojos que le aproximan a otros pintores del momento y, en especial, a la Escuela sevillana ya que a la mente vienen las obras de Diego Velázquez o de Alonso Cano, artistas en cuyas composiciones, este preciso color es muy fácil de encontrar, tanto en temas religiosos como en retratos, a modo de bandas u otros tejidos que acompañan al retratado. Baste recordar el precioso juego de tonalidades que consigue Velázquez en «La Coronación de la Virgen» del Museo del Prado.

El manto que cubre el hombro izquierdo de María queda oscurecido por la suciedad aunque el azul, que a primera vista parece negro, no ha de diferenciarse mucho del manto del

\footnotetext{
2 Ver Caturla, M.L.: «Zurbarán en Llerena», Archivo Español de Arte, 1947, n 80, p. 270.

${ }^{3} \mathrm{El} 10$ de febrero de 1642, Paula emprende una acción jurídica contra su padre por cuestiones de herencias acaecidas en 1640; es aquí donde se declara «doncella». En 1659 aparece casada con el Capitán Pedro Martínez de Soto, Alcalde de las Relaes Aduanas. Ver Kinkead, D.I.: «The last sevillian period of Francisco de Zurbarán», Art Bulletin, junio, 1933 , p. 310.

${ }^{4} \mathrm{~J}$. Baticle considera que el pintor utilizó a su hija Manuela para la «Inmnaculada Concepción» (Colección Plácido Arango, Madrid) fechada en el año 1656 (Ver Baticle, J.: Catálogo de la Exposición «Francisco de Zurbarán», Museo del Prado, 1988, pp. 101 y 354). Se trata de la única hija que sobrevivió del tercer matrimonio que contrajo el artista con Leonor de Tordera y que debió de nacer hacia 1649-1650. La diferencia de edad entre el pintor y la niña y el hecho de que fuera la única que sobreviviera del matrimonio, pudieron hacer que aquél se volcara en este cuadro.
}

AEA, LXXVI, 2003, 302, pp. 187 a 205 
Salvador en el Museo del Prado al que antes hemos aludido o del que aparece en los cuadros del retablo de la Defensión, también mencionados.

Centrándonos en el estudio de las manos, en los cuadros de la Cartuja, la Virgen se encuentra, desafortunadamente para nosotros, con ellas separadas, no así en las representaciones de la Inmaculada Concepción, como la del Museo del Prado, la del De Arte de Cataluña o la que se encuentra en Sigüenza, posiblemente la que más se aproxima de todas a la nuestra en este aspecto. Se trata de manos toscas pero de volúmenes muy marcados, dado el fuerte contraste de luz y de sombra al que están sometidas. Un tipo de tratamiento que nos recuerda la imagen de María en «La adoración de los Reyes Magos» pintada por Velázquez en Sevilla en su etapa juvenil y conservada en el Museo del Prado.

Si estudiamos los efectos lumínicos, la composición se encuadra dentro del tenebrismo que caracterizó al menos la primera etapa en la pintura del artista extremeño. No se le puede discutir a Zurbarán la maestría en el tratamiento de la luz artificial que contribuye, si cabe, a reforzar el ambiente de devoción que se desprende de la expresión de recogimiento de María. Volvemos a recordar el modo de hacer de los sevillanos, y más concretamente del que los seguidores de Pacheco hacían de este elemento tan importante en Pintura. Una luz casi sobrenatural que queda acentuada por el fondo oscuro y que sirve para dar más fuerza a la figura.

Desde una perspectiva cronológica, su semejanza con los cuadros arriba mencionados nos permite fechar la obra hacia los postreros años de la década de 1630. El cuadro de la Defensión, «La adoración de los pastores», está fechado y firmado en una tarjeta, abajo a la izquierda: «Franco de Zurbaran. Philippi III Regis Pictor Faciebat 1638 a.d.» ${ }^{5}$. Es evidente que un cuarto «I» ha desaparecido y se trata de Felipe IV. Por su parte, la imagen de «El Salvador bendiciendo» del Museo del Prado, está firmado y fechado en $1638^{6}$. La «Inmaculada Concepción» del Museo de Sigüenza (Fig. 4), con la que queremos ver parecidos en las manos, carece de fecha conocida; J.Baticle la dató hacia el año de 1636, cuando se extendió por Sevilla la costumbre de representar a María con una túnica blanca, frente a la roja utilizada con anterioridad ${ }^{7}$. Estos tres ejemplos nos permiten arriesgar una fecha de realización próxima al año de 1640, dada la semejanza entre todos ellos.

El propósito de la obra bien pudiera ser un encargo privado que coincidió en el tiempo, aunque un poco posterior, dada la edad de la joven, con los cuadros ya mencionados del Salvador del Prado o de la serie de la Cartuja de la Defensión en Jerez de la Frontera, lo que fue aprovechado por nuestro artista para utilizar la misma modelo e idénticos recursos compositivos.

La maestría de Zurbarán en este cuadro es evidente. Sorprende la economía de medios representativos. La figura carece de símbolos que la identifiquen y aún así sabemos perfectamente de qué imagen se trata. El magnífico juego de gestos del rostro y de las manos, el extraordinario tratamiento de luces y sombras nos invitan a rezar con ella. La pintura, además, presenta el típico cuarteamiento que aparece en cuadros del siglo XviI, lo que le hace todavía más evocadora.

En resumen, nos encontramos ante una obra inédita de Francisco de Zurbarán, de una calidad extraordinaria y que, desde una perspectiva iconográfica, contribuye a reforzar la temática del pintor puesto que se trata de un tema, el de la Madre de Dios, sola en un cuadro, que no tenía representación en su producción hasta este momento.

$M^{a}$ Del Mar Doval Trueba Doctora en $\mathrm{H}^{\mathrm{a}}$ del Arte, U.C.M.

\footnotetext{
${ }^{5}$ Ver Baticle, J.: Catálogo de la Exposición «Francisco de Zurbarán», Museo del Prado, 1988, p. 264.

${ }^{6}$ Op. cit., p. 394.

${ }^{7}$ Op. cit., p. 345.
} 